\title{
ADMINISTRAÇÃO
}

\section{Patrão Versus Empregado na Administração Pública - Posição do DASP}

\section{Raimundo Xavier de Menezes}

«Pour chaque chef, le but du commandement est de tirer le meilleur parti possible des agents qui composent son unité, dans l'intérêt de l'entreprise.» Henri Fayol - Administration Industrielle et Générale.

P

ARA melhor compreensão do fenômeno DASP e da peculiaridade de sua atuação na Administração Pública Federal Brasileira faz se mister uma análise atenta do binômio Patrão Empregado, como norma de comportamento sempre presente na vida social de tôdas as comunidades humanas.

Com efeito, seja nos grupamentos primitivos de povos subcivilizados, seja nos futuros Estados, ou Unnião universal, concebidos em harmonia com os mais aperfeiçoados principios de indole socialista, a separação e defesa mútua dos interêsses individuais e coletivos exigirá sempre uma estrutura organizada em graus hierárquicos ascensionais, ensejando a coexistência dos que mandam e dos que obedecem, dos que reivindicam e dos que concedem, dos que orientari e dos que cumprem etc., num permanente relacionamento de deveres e responsabilidades, imprescindivel à concretização dos anseios de progresso individual ou coletivo inerentes à alma humana.

$\hat{E}$, evidentemente, o conflito tese-antitese de caráter eterno e universal, aว qual o homem não pode furtar-se, sem declinar de sua condição de ser sujeito-objeto, agente e paciente. Viver é lutar, diz bem o refrão. Viver, é claro, no sentido positivo de desenvolver.s?, progredir, realizar uma missão, esforçar-se por atingir um fim, consciente ou inconscientemente. Lutar, ou seja, debater se num jôgo de oposições de fôrças, num continuo processamento de formações de sinteses, conseqüentes da conciliação de correntes antagônicas que se chocam e tendem a fundir-se ou anular-se. 
Prêso inelutàvelmente a essa fatalidade, não pode o homem afastar-se, um instante sequer, dêsse processo dialético, sem pôr em risco seu destino, fadado a ver irrealizáveis seus intentos e baldados todos os esforços.

Essa pressão, que impulsiona como um todo a máquina da História, efetiva-se atuando em caráter particular, mas de modo idêntico, setorialmente, em áreas limitadas, especializadamente definidas, abrangentes, num somatório, da totalidade do processo evolutivo.

Se bem que velha quanto a própria Humanidade, esta Lei, só com a sistematização da Economia como ciência, foi conscientemente elucidada, definida e concebida em têrmos de generalização. Nada mais próprio, portanto, que utilizá-la para esclarecer um fenômeno comumente constatado no âmbito dêste campo do saber humano, ou seja, a configuração do binômio Patrão-Empregado, realçando a significação que isto apresenta para explicar a razão de ser e proceder do DASP como instituição condicionadora da evolução histórica brasileira.

Evidentemente, o progresso humano origina-se em virtude de causas diversas: diretas e indiretas, mediatas e imediatas, próximas e remotas, precisas e aleatórias, pràticamente indefiniveis nas suas determinações. Entretanto, a experiência e o saber demonstram que, com raizes na própria alma humana, o desejo ou ânsia do indivíduo autofirmar-se perante seu grupo e assegurarse em posição firme ao correr do tempo, leva as pessoas a dedicar esforços no sentido de construir algo excedente de suas necessidades temporárias e acumular êsse algo para uso próprio e. por extensão, de seu grupo, que é formado na base de interêsses comuns.

Essa circunstância impeliu o homem primitivo a mobilizar esforços, a fim de melhor, mais eficientemente, conseguir a realização de seu objetivo. Para tanto não lhe foi impossivel aliciar a colaboração de outros indivíduos e reuni-los num só grupo concebido à base de comunidade de interêsses.

A necessidade ou imperativo de especialização de funções com o conseqüente aproveitamento em graus diversos de capacidades individuais estratificou tais organizações incipientes, ensejando as superposições de camadas distintas, caracterizadas pela maior ou menor faculdade de mando e obediência, conforme as injunções predominantes em relação a cada um dos elementos integrantes do grupo.

Mesmo nesse estágio de desenvolvimento social já estão presentes os caracteres conflitantes, que mais tarde ensejaram, de modo inevitável, a segregação, dentro do grupo, em posições antagônicas, dos dirigentes e dirigidos, em busca de melhores situações para apaziguar instintos desde então já arraizados na alma humana. 
O empreendimento individual onde um só decidia e executava; o empreendimento familiar com distribuição de funções e diferenciações hierárquicas, mas existindo comunidade de interêsses; e, finalmente, o empreendimento coletivo onde a comunidade de interêsses desintegrou-se em objetivos distintos, constituem, tudo indica, etapas dêsse processo evolutivo.

No ponto a que chegou nossa análise, já podemos encarar empreendimentos coletivos, onde dois grupos de interêsses - o do proprietário e o dos empregados - conflituam dialèticamente em têrmos de tese e antítese, para como sintese resultar o progresso social. A fase anterior a êsse estágio de desenvolvimento era aquela em que o indivíduo, trabalhando isoladamente, confundia com os seus próprios os interêsses do empreendimento, e tôdas as operações eram realizadas à causa, exclusivamente, de esforços individuais.

Convém abrirmos aqui um parêntese para deixar claro que êsse progresso se desenrola em função do meio e não do tempo, podendo haver a contemporaneidade de estágios, desde os mais primitivos, aos mais adiantados, dentro da mesma área de observação.

Como etapa seguinte surgiram as instituições fisicamente despersonalizadas pelo caráter coletivo de suas formações, orientadas, porém, ainda, no sentido de dirigir esforços para acrescer os recursos de seus promotores na proporção em que foram investidos. Evidentemente, essa diretriz contrapunha-se flagrantemente aos objetivos daqueles colaboradores que não contribuiram com recursos para a formação da emprêsa, ou sejam, os empregados. Permaneciam, assim, ainda bem definidos os campos de atuação dos dois grupos e bem vivo, conseqüentemente, o conflito resultante do choque de interêsses em luta.

Ainda aqui ambas as partes ocupavam posições bem definidas e podiam ter sua açâo motivada por aspirações inconfundiveis, quais sejam o sentimento de posse e o desejo de conquista, oriundos um e outro do mesmo instinto natural inerente à pessoa humana, apenas defasado, em relação aos individuos, na sua gradação de intensidade.

Mais um passo nessa evolução, encontramos configuradas as entidades de feição eminentemente social, seja pela origem, seja pela forma e destinação.

Desapareceu, então, a figura clássica do proprietário e surge, concebida abstratamente, a personalização do interêsse coletivo.

$\mathrm{Na}$ época atual, o inapa da sociedade está intensamente pontilhado de entidades dessa natureza. Em todos os quadrantes do Universo, apresentam-se elas sob múltiplos e diversificados aspectos, variando de maneira substancial em graus de complexidade e modos de disciplinamento. 
Como expressão máxima dessa evolução, temos no Brasil, entre outras, as sociedades por ações, as cooperativas e as entidades de direito público.

Em tôdas essas organizações, onde não pode ser o proprietário individualizado, alguém terá que assumir as funções clássicas do patrão para assegurar o equilibrio funcional da emprêsa e não deixá-la afastar-se do rumo certo, que conduzirá à realização dos objetivos colimados.

Nessas hipóteses há necessidade, portanto, da instituição de um corpo dirigente para cada uma dessas entidades, incumbindolhes, além da realização dos planos programados, assegurar. sem desrespeitar os cânones do bem público, não só a manutenção como o progresso do patrimônio coletivo deixado sob a sua guarda. $\hat{E}$ fora de dúvida que tal atitude se contrapõe àquela peculiarmente, por inclinação natural, adotada pelos empregados, segundo a qual o máximo de resultados positivos deve ser conseguido, em benefício próprio, com o minimo de esforços despendidos.

O curioso e desconcertante do problema é que muitas vêzes também são empregados da instituição os elementos componentes de seu corpo diretor, como ocorre, comumente, no caso das entidades de direito público, de que é expressão máxima o Estado, ou União Federal, no exemplo brasileiro.

Não obstante, a generalização da condição de empregado a todos os componentes da mesma organização, a boa prática administrativa requer, imperativamente, a existência daquela dualidade de atitudes para estabelecer o conflito gerador do progresso.

Como na pequena emprêsa, nas de maior vulto há funções típicas do patrão. A diferença é que funções da mesma natureza, no primeiro caso, são exercidas por um só indivíduo - o empregador - e no segundo, à medida que se avolumam, ocupam turmas cada vez mais numerosas, chegando-se até a exigir, para pleno êxito de execução, a institucionalização, em órgãos complexos, convenientemente estruturados e aparelhados com amplos recursos indispensáveis à consecução de seus objetivos.

Assim, enquanto na primeira hipótese o empregador, êle próprio, por exemplo, faz tôdas as verificações e adota as providências requeridas para recrutamento, admissão, retribuição, contrôle de produtividade, promoção, dispensa etc. de seus empregados, na segunda, tais funções, a par de outras, terão que ser institucionalizadas, ensejando a existência de órgãos específicos, para cuidar-lhes da execução.

Foi isso, precisamente, o que ocorreu na Administração Pública Federal Brasileira com o aparecimento do DASP. Pelas suas origens, pela sua posição, pelas suas finalidades é êste ttm órgão eminentemente patronal, e só olhado sob êsse prisma será possivel compreendê-lo e explicar a razão da indole de seu comportamento. 
Tal qual seus congêneres existentes no estrangeiro, em países altamente desenvolvidos, como os Estados Unidos da América, Inglaterra, França etc., propõe-se o DASP, corretamente, na sua esfera de competência, zelar pelos interêsses do Estado - o patrão - seja adotando medidas tendentes a obter maior eficiência da máquina administrativa, seja refreando o avanço de incursões de caráter reivindicatório, não importa qual a procedência. No seu âmbito de ação, o normal é sempre exigir mais do que conceder, reconhecer, se fôr o caso, em vez de postular, opor-se à conquista e resistir na defesa, sempre que esteja em jôgo o interêsse coletivo.

Contra essa muralha de obstáculos também se chocam os interêsses do funcionalismo público, em essência antagônicos ou irreconciliáveis com tal norma de comportamento. Eis por que com insistência se ouve a alegação de que o DASP é contra - funcionalismo, em relação ao qual se supõe sempre disposto a não reconhecer-lhe os direitos e negar qualquer concessão, por minima que seja.

É êste um conceito na generalidade dos casos fruto da incompreensão. Se se atentasse para o fato de que a cada órgão deve corresponder uma função e tôda ação deve desenvolver-se coerentemente com o propósito que a anima, impossivel seria fugir. de boa-fé, à conclusão, segundo a qual se afigura lógico o comportamento do DASP.

O êrro não reside na existência do DASP ou no feixe de atribuições que encerra, mas sim na falta de agentes específicos para exercer o papel que impròpriamente se intenta atribuir àquele órgão, ou, em decorrência dessa lacuna, se procura evitar que êle assuma. Seria o mesmo que no processo judiciário, na omissão da defesa, exigir-se que dela também se encarregasse o promotor, ou, em virtude da mesma circunstância, êsse agente suprimisse ou amenizasse seu pronunciamento.

A ciência da administração é uma só e seus princípios aplicamse igualmente na pequena e na grande emprêsa, no setor privado e nos negócios públicos. A experiência e o saber acumulados neste campo do conhecimento humano demonstram, de modo insofismável, a validade dessa conclusão.

O Estado é inegàvelmente uma emprêsa, se bem que de âmbito descomunal e, portanto, apresentando uma dose maior de complexidade. Essa circunstância, porém, do ponto-de-vista administrativo, não o torna essencialmente diferente de uma pequena indústria ou casa comercial. Aliás, há emprêsas privadas que em vulto se sobrepõem a muitos Estados estrangeiros convenientemente organizados.

Tanto nas entidades de direito público como nos estabelecimentos de caráter privado, não são elimináveis os conceitos de patrão e empregado e, a par da almejada cooperação existente 
entre ambos para ensejar o êxito do empreendimento, há, impreterivelmente, interêsses que se contrapõem e os separam em campos conflitantes. Uns e outros devem estar em situação de equilibrio, aparelhados para essa luta, munidos das armas próprias para se debaterem construtivamente pela conquista de vantagens visualizadas, segundo a perspectiva descortinada de suas posições particulares.

Em têrmos de possibilidades humanas, afigura-se lirico e impossivel o sonho anarquista, seja no todo absoluto, seja na parte infinitesimal. O conflito sempre existiu e existirá como atributo da congregação de esforços comuns, na defesa de interêsses particulares, no cenário social.

Não adianta desconhecer o fato, mas sim encará-lo dentro da realidade e é precisamente isto que não foi feito no caso da Administração Pública Federal Brasileira. O problema só foi considerado pela metade ao se instituir um órgão de indole patronal com tendência a agir discricionária ou paternalmente, pela impossibilidade de cotejar, com a sua, realidade filtrada através de mentalidade diametralmente diferente. Se bem que justificada a existência do órgão em face dos bons principios de administração, êsse êrro de posição e perspectiva acarreta distorções insanáveis em seu funcionamento, em grande parte responsáveis pelo seu desconceito.

Nunca, porém, será tarde para remediar ou, no mínimo, evitar que se agravem as complicações existentes no quadro clínico identificado.

Com êste artigo busca-se, precisamente, êsse objetivo, isto é, ensejar uma ação saneadora, calcada em nitida compreensão do problema.

Sintetizando todo o exposto, poderemos chegar às seguintes conclusões:

- o binômio Patrão-Empregado apresenta-se como uma constante, de caráter eterno e universal, dentro dos grupamentos humanos particulares ou socialmente constituídos;

- o mútuo anseio de progresso coloca ambos os têrmos em posições antagônicas dentro de cada grupamento, gerando-se um conflito dialético conducente à realização daquele objetivo comum;

- com o desenvolvimento social desapareceu a figura do patrão - proprietário, onipresente e atuante, cujo papel, considerado imprescindivel, passou a ser atribuído a pessoas sujeitas também à condição de empregado;

- conforme a amplitude da emprêsa, o volume de atribuiçóes de natureza patronal chega a ser de tal ordem que enseja a institucionalização de órgãos específicos e especializados;

- tal hipótese ocorreu, precisamente, na Administração Pública Federal Brasileira, dando lugar ao surgimento do DASP 
como órgão de execução e assessoramento ligado à Presidência da República;

- do ponto-de-vista técnico, justifica-se plenamente a existência e modo de atuação do DASP no quadro da administração brasileira, em consonância com exemplos salutares oferecidos por paises estrangeiros mais evoluidos;

-- entretanto, seja por incompreensão generalizada quanto à missão cometida ao DASP, seja por concepção errônea do dimensionamento de sua área de competêricia, é êle, freqüentemente, mal visto por gregos e troianos;

- é oportuno reconhecer que houve um falseamento da realidade ao criar-se o DASP, sem se cogitar de equilibrar sua ação mediante o oferecimento ao funcionalismo de meios adequados de contra-argumentar de igual para igual, dando testemunho da realidade vista do ângulo de seus próprios interêsses;

- impõe-se um nôvo equacionamento do problema, para efeito de solução mais consentânea com as aspirações de progresso que alicerçaram a idéia de criação do DASP. 